\title{
Her yönüyle fellow eğitimi
}

\author{
Fellowship training in all aspects
}

\author{
Kaan Irgit
}

Liv Hospital, Ortopedi ve Travmatoloji Kliniği, Beşiktaş, İstanbul

\begin{abstract}
Ortopedi ve travmatoloji eğitiminde asistanlık sonrası süreçlerden birisi de fellowship eğitim programlarıdır. Bu programlar Dünyada çeşitli ülkelerde ve çeşitli şekillerde verilir. Hepsinde amaç ortopedistin kişisel ve mesleki gelişimini arttırmasıdır. Bunlar zorunlu eğitimler değildir, ancak hızla gelişen ve ilerleyen bilim dünyasında kısa zamanda çok tecrübeli meslektaşlarımızdan eğitim almak için etkin araçlardır. Temel olarak fellowship programları klinik, araştırma ve gezici (travelling) olarak üç şekildedir. Herhangi birine başvurmanın sebepleri ve yolları birbirinden ayrılır. Aşağıdaki yazıda, fellowship programlarının tanımları, amaçları ve başvuru yolları üzerinde durulmuştur. Ülkemiz klinik fellowship programları Batı ortopedi dünyasının gerisinde kalmıştır; ancak temenni odur ki, günümüzde eğitimde uygulanan akreditasyon ve standartlaşma çalışmaları sonrasında, önümüzdeki yıllarda istenilen düzeye gelecektir.
\end{abstract}

\begin{abstract}
Fellowship training is one of the learning processes after orthopaedic residency. There are certain fellowship programs in many countries. Fellowship training is not mandatory. However, they are efficient ways to learn from experienced orthopaedic surgeons in the rapidly growing orthopaedic world. Basically there are three different fellowship programs: clinical, research and travelling fellowhip. They all have different application routes. This paper is describes the fellowship programs, and describes the aims and application ways of these programs. Turkish orthopaedic education lacks valid clinical fellowship programs, however, there is a rapid standardization and accreditation endeavor by the educational committee that hopefully help to build better national fellowship programs.
\end{abstract}

E ski İngilizce'de "félagi” kelimesi arkadaş, eşlik eden, refakat eden ve iş ortağı demektir. "Félagi" kelimesinin yeni İngilizce'de karşılığı "fellow”dur. "Fellow" çalışan kişiye verilen isim iken, bu pozisyona da "fellowship" denir. Kelime karşılığı dilimizde tam olarak yer almadığından, yazının bundan sonraki bölümünde "fellow" olarak kullanılacaktır. Dilimizdeki "çırak" kelimesi belki de bu pozisyonu açıklamak için kullanılabilecek tek kelimedir. Ancak, çıraklar genelde ustalarının yanında çalışmaya devam ederken, fellow'lar öğrenim ve eğitim süreçleri sonrası genellikle başka yerlerde çalışmaya devam eder ve nadiren eğitim aldıkları yerlerde çalışma imkânı bulabilirler. Ortopedide fellowship çeşitli şekillerde yapılabilir. Bu pozisyon genellikle doktora sonrası eğitim programıdır (postdoctoral); yani, doktora eğitimi karşılı̆̆ı olan asistanlık eğitimi sonrasında yapılır.
Genel olarak ortopedide fellowship eğitimi üçe ayrılır: klinik fellowship, araştırma fellowship (research fellowship) ve gezici fellowship (travelling fellowship) pozisyonu. Hepsinde amaç, temelde bir alt dalda bilgi ve becerilerin arttırılmasıdır. Dilimizde karşılığı olmadığı gibi, maalesef ülkemiz tip eğitiminde de fellowship eğitimi alma olanakları kısıtlıdır. Ortopedide resmi klinik fellowship eğitimi kısıtlı olarak el cerrahisi ve omurga cerrahisinde verilmekte iken, diğer alt dallarda bu imkân hemen hemen yoktur. Resmi olmayan, yani bir sertifikasyon olmadan fellowship eğitimi veren merkezler ise mevcuttur.

Fellowship pozisyonları, Amerikan tıp eğitiminde kısaca PGY (postgraduate year) olarak geçen, yani mezuniyet sonrası eğitimin birinci yılına eşit bir eğitim seviyesi olarak görülür ve maaşları da genelde bu şekilde belirlenir. İsteyen her kurum fellow eğitimi veremez. Belirli kriterlerin yerine getirilmesi beklenir. Öncelikle, bu

- İletişim adresi: Op. Dr. Kaan Irgıt, Liv Hospital, Ortopedi ve Travmatoloji Kliniği, Ahmet Adnan Saygun Cad. Canan Sok. No: 5, Ulus, Beşiktaş, İstanbul Tel: 0312 - 4261450 / 534 e-posta: kaanirgit@yahoo.com

- Geliș tarihi: 24 Ekim $2014 \quad$ Kabul tarihi: 24 Ekim 2014 
eğitimi verecek o yan dalda yetişmiş yeterli sayıda uzman olması gerekir. Daha sonra da o yan dal eğitimini layıkıyla alabilmek için yeterli sayı ve çeşitlilikte hasta ve olgu olması gerekir. Bundan sonraki en önemli gereklilik ise maddi kaynaktır. Fellow'ların maaşlarının belli bir maddi kaynaktan sağlanması gerekir ki bu, araştırma fellowship pozisyonlarında daha öne çıkan bir problemdir. Bir fellow maaşı Amerikan standartlarında genelde \$2000-3000 arası değişmektedir. Bu değişim eyaletten eyalete, yaşanan bölgeye veya hastanenin kaynaklarına göre değişiklik gösterir. Bu gereklilikleri yerine getiren klinikler akreditasyon için başvuruda bulunurlar ve yeterlilikleri her yıl tekrar denetlenir.

\section{KLINIK FELLOWSHIP PROGRAMLARI}

Öncelikle bilmek gerekir ki bu tamamen isteğe bağlı yapılan bir fazladan yan dal eğitim tercihidir. Herhangi bir klinik fellowship programı temelde bir cerrahi ve klinik beceri geliştirme programıdır. Başvuran kendini belli bir konuda daha da geliştirmek istiyorsa ve buna değecek ise yapılmalıdır. Başvuran böyle bir pozisyon sonrası üç şey kazanır: 1) belli bir konuda ortopedik beceri, 2) bu becerilerin kanıtı olan bir belge ve 3 ) aynı şeklide çalışan ve düşünen bir grup ortopedist ile çalışma ve iletişim ağı içinde olma avantajı ve olanağı. ${ }^{[1]} \mathrm{Bu}$ arada, bu eğitim süreci ile geçen yıl genel ortalamanın altında maddi kazanç olacak bir yıl olacağından, tercih edilen merkez ve verdiği eğitim buna değmelidir. Bu ekstra eğitim yılı, bir nevi mesleki bir yükselme basamağı olarak düşünülmelidir. İyi bir fellowship eğitimi 6. yıl asistanlığından daha fazla bir durumdur; klinik idare becerilerinin ve hasta hakkında kritik karar verme yetilerinin de bağımsız bir düşünme süreci ile gelişmesini sağlamalıdır. Tercih edilen programın daha önceki mezun fellow'ları ülkelerinde hangi pozisyonlara gelmiş, buna da bakmak gerekir ki o programı daha iyi değerlendirmek ancak bu şekilde mümkün olur. Büyük şehirlerdeki programlarda, alınacak maaşın yetmeyebileceği ve ekstradan $\$ 20.000$ gerekebileceği akılda tutulmalıdır. Seçilecek bölümde fakültenin yani eğitimcilerin birbirleri ile uyumsuz ve kavgalı olmaması da ayrıca bir tercih sebebi olmalıdır. Bu programlarda, nöbetlerin ne kadar sık olduğundan çok ne kadar verimli geçtiği de önemlidir. Fellow seviyesinde ortalama 350 ameliyat yapılması idealdir (el cerrahisinde biraz daha fazla, omurgada biraz daha az).

Başvurmadan önce, kişi gelecekteki mesleki beklentileri konusunda kararlı olmalıdır. Zayıf ve kuvvetli yanlarını bilip zayıf yanlarını geliştirmek amacında olmalıdır. Bu alanda hizmet veren merkezlere, iyi yazılmış bir özgeçmiş ve cover letter (kapak yazısı: başvuranın kendisini ifade ettiği bir kısa özet yazı) mektubu ile başvurulur. Bu mektubun kısa, çarpı ı ve net olması gerekir. Başvuran kişi bu mektubu yazarken, ne istediğinden emin olmalı ve bunu güzel bir dille ifade etmelidir. Bu başvuruları yaparken kaynak olarak internetten ve daha önce tecrübesi olanlardan yararlanılabilir. ABD'de bu programlara kabul edilme bir eşleşme (match) programı ile olduğundan, sadece bir merkezi istemek veya merkezin sizi istemesi yetmeyebilir. Mutlaka her üç USMLE (United States Medical Licensing Examination) sınavını da başvurudan önce almak gereklidir. Sadece el cerrahisi yan dalı bu kural için istisnadır. Her kabulde olduğu gibi güçlü tavsiye mektupları gerekir. Cerrahi yan dal pozisyonları da her yıl duyurulur. Bu programların hemen hepsi birer yıllıktır. Dünya'nın her yerinde, bu tip başvurular iyi yazılmış bir özgeçmiş, konudaki isteğinizi belirten bir cover letter ve güçlü tavsiye mektupları ile olacaktır. Çok rahat anlaşıp konuşabilecek seviyede İngilizce (genellikle İngilizce konuşulan ülkelere gidildiğinden veya çoğu Avrupa ülkesinde yeterli olduğundan; ancak, gidilen ülkeye göre bilinmesi gereken dil değişiklik gösterebilir) bilmek gereklidir. Japonya ve Güney Kore gibi ülkelerde de el cerrahisi veya omurga cerrahisi ile ilgili çok üst düzey eğitim veren fellowship programları mevcuttur. Planlama yaparken, fellow eğitimi sonrasını da hesaba katmak gerekir. Düşük maaş ile 1-2 sene eğitim almak herkesin yapmak isteyeceği bir şey değildir. Getiri ve götürülerini, kişinin kendi sosyal ve mesleki beklentilerine göre belirlemesi gerekir. Ailesi olanlar için, gidilecek yerdeki okul olanakları ve sosyal çevre de büyük önem taşır.

\section{ARAŞTIRMA FELLOWSHIP PROGRAMLARI}

Bunlar, bir alt dalda bilimsel araştırma yapmayı öğreten programlardır. Bu programlarda genellikle klinik araştırmalar yapılır, ancak laboratuvar çalışmaları ve hayvan deneyleri yapma ve öğrenme şansı da vardır.Başvuran kişi yine amacını iyi belirlemelidir. Asistanlık eğitim sürecinde iyi bir bilimsel araştırma yapma alt yapısı almış bir kimsenin bu programlara ihtiyacı olmayabilir; dahası, iyi bir araştırmacı olmak veya bilimsel araştırma yapmak için bu fellowship'lik eğitimini almak zorunlu değildir. ${ }^{[2]}$ Bu anlamda, nereye başvurulacağından çok, kişinin kendine su soruları sorması önemlidir: "Benim bilimsel araştırma yapma kapasitem nedir? Mesleki amaçlarım nelerdir?” lyi bir bilimsel araştırma özgeçmişi, klinik fellowship başvurularında çok etkili olabileceği gibi yaşanacak olan ülkeyi ve sistemini tanımak için de iyi bir firsattır. Böylece, klinik fellowship için bir basamak olarak da kullanılabilir. Araştırma fellowship eğitiminde, iyi bir mentor çok önemlidir. Araştırma yapılacak grupta en az bir tane çok iyi araştırmacı olmalıdır. 
Araştırma fellowship programlarında kişi bir araştırma yaparken, planlama yapmayı, metodolojiyi ve hipotez seçmeyi öğrenir. Ayrıca, etik kurul isteği yazılmasını ve uygun şekilde makale değerlendirmesini de öğrenme şansı yakalar; istatistik bilgisini geliş̧irebilir; en önemlisi, kaynak araştırma ve dergilere başvuru süreçlerini öğrenir. Genelde araştırma fellow programları iki yıldır ve bu sürede çeşitli sayıda makale yazma ve katkıda bulunma olanağı da yakalanır. İlk yıl, sistemi öğrenmek ve araştırma konularını belirleyerek etik kurul onaylarını almakla geçer; ikinci yılda ise, genelde ilk yılın meyveleri alınır ve o yıl makaleleri yazmak ve dergilere göndermekle geçer. Fellowship'in bir diğer avantajı, başka tecrübeli araştırmacılar ile tanışma ve çalışma imkânıdır. Bu arada, büyük bir dezavantajı, bu bir veya iki yıllık süre boyunca cerrahi pratikten uzak kalmaktır ki, başvuranın bunu göz önünde bulundurması gerekir. Ancak, gözlemci olarak çeşitli olguları izleme imkânı olacaktır.

Araştırma fellowship pozisyonları için USMLE sınavları gerekmez. Bunlar, www.orthogate.com gibi sitelerde duyurulur. Aynı şekilde Orthopaedic Research Society'nin www.ors.org sayfasından da mentor ve program seçimi için yararlanılabilir. TOTBID çatısı altında kurulan Türk Ortopedik Araştırma Konseyinden de (TOAK) bu konuda destek alınabilir. Araştırma fellow'luğu, ileride akademik kariyer yapmak isteyenler için makale yazmak, insan tanımak, araştırma bütçesi oluşturmayı öğrenmek ve beraberinde klinik ve araştırmaları da yürütmeyi öğrenmek için bulunmaz bir firsat olabilir.

\section{GEZICI FELLOWSHIP PROGRAMLARI}

Bu programlar, ilgilendiğiniz alanda kısa sürede yoğun bilgi ve beceri almanın güzel bir yoludur. Genelde, büyük ortopedi cemiyetlerinin özellikle 40 yaş altı genç uzmanları cesaretlendirdiği bir sistemdir. Hem çeşitli ülkelerin tıbbi seviyesini öğrenmek, hem değişik cerrahi kültürleri ve yaklaşımları görmek, hem de sosyal ağ yaratmak için çok yararlıdır. Başvuru kriterleri olarak genelde, o cemiyete üye olmak, son iki toplantısına katılmak ve o alanda yayın yapmış olmak sayılabilir. Süre sonunda, katılımcılardan genelde bir rapor veya sunum yapması istenir.

Sonuç olarak, fellowship programları zorunlu olmayan, kişinin mesleki kariyer planlamasında eksiklerini gidermek veya belli konularda daha ayrıntılı eğitim almak için tercih edebileceği bir eğitim sürecidir. Seçilecek klinik ayrıntılı olarak araştırılmalıdır ve kliniğin başındaki mentor çok önemlidir. Kişinin çok geniş bir mesleki ve sosyal çevre edinmesine katkıda bulunur. Bu geçen sürede alacağı maaş, normalde kazanacağından çok daha az olacaktır; bu hesaplamalar iyi yapılmalıdır. Akılda tutulması gereken bir diğer konu; bu programların oldukça yorucu ve yoğun programlar olduğudur. Fellow, süre bitiminde o konudaki özgüvenini ve tecrübesini üst noktalara taşıma şansı yakalayacaktır; ancak, bunun bir bedeli vardır. Fellow' dan beklenen, sürekli çalışması ve üretmesidir. Bu programların kişiye katkısı, kısaca; eğitim, bilimsel araştırma yapmayı öğrenme, liderlik becerilerini geliştirme, sağlık hizmetini öğrenme, klinik bütçelerini planlamayı öğrenme ve mesleki gelişim olarak özetlenebilir. ${ }^{[3]}$ Ümidimiz odur $\mathrm{ki}$, ülkemizdeki eğitimin standardizasyon çalışmaları en kısa zamanda meyvesini verir, Dünya çapında fellow eğitimi veren kliniklere sahip oluruz ve böylece, meslektaşlarımız kendi diliyle bu eğitimleri alırken, küçülen ve bütünleşen ortopedi dünyasında, başka ülkelerden gelen meslektaşlarımıza da bu eğitimleri verme imkânına kavuşuruz.

\section{KAYNAKLAR}

1. Bernstein J. Factors to consider when considering a fellowship. Clin Orthop Relat Res 2006;449:215-7.

2. Ahn J. Research fellowships. Clin Orthop Relat Res 2006;449:239-40.

3. Biant LC, Rangan A, Costa ML, Muir DC, Weinrauch PC, Clasper JC, Dix-Peek SI. The ABC Travelling Fellowship 2010. J Bone Joint Surg Br 2010;92(11):1498-CrossRef 